\title{
The impact of organizational commitment on upgrading ERP for maintaining the quality of information and the ERP performance
}

\author{
Mikhail Gnevanov ${ }^{1}$, Anastasya Sharlaimova ${ }^{1, *}$ \\ ${ }^{1}$ Higher School Of Economics, Russia, Myasnitskaya Ulitsa, 20, 101000 Moscow
}

\begin{abstract}
This study examines the impact of organizational commitment on upgrading ERP for maintaining the quality of information and the performance. Many manufacturing companies in East Java have been implementing ERP in managing their business. Although the ERP postimplementation has been continuously maintained by these companies, the inevitable changes and development in the current business practices have forced them to upgrade their ERP infrastructure. All ERP system upgrades require a commitment from both management and employees, which is also known as the organizational commitment. This research used the employees of 110 manufacturing companies in the region of East Java, which have been implementing ERP for more than two years. The response rate is quite good, as many as 90 questionnaires out of 110 distributed questionnaires are completed by the respondents. Data analysis has been performed using partial least square (PLS) technique. The result demonstrated that the organizational commitment brings a significant impact to the ERP infrastructure upgrade. The organization commitment shows a significant impact on the information quality, but does not show a direct impact towards the ERP performance. Similarly, the ERP infrastructure upgrade also shows a significant impact on the information quality, but does not show a direct impact on the ERP performance. The information quality has a positive impact on the ERP performance. In total, the organizational commitment directly and indirectly affects the ERP performance. The management commitment empowers the key user to be aware of the ERP system upgrading all the time. Keeping ERP to the most up-to-date condition will contribute to the high quality of the information. Furtherly, the best information quality provides the appropriate information in term of the right time and the right information in the decision making process. The appropriate information enables the top management to make decisions in the pursuit of improving the company's performance.
\end{abstract}

\section{Introduction}

The intensity of business competition has forced manufacturing companies to build the business system to survive the competition at the global level. Dealing with global competition, management should be building an integrative information technology (IT) system to raise the synergy between departments which will produce a more effective and efficient process. On the industry level, the implementation of IT will create a better competitiveness by making it easier to acquire accurate data, and improving the

\footnotetext{
* Corresponding author: shura1501@yahoo.com
} 
information infrastructure for companies [1]. The IT implementation in the form of ERP technology needs to be continuously maintained by the company. The previous research has been discussing the critical success factors in ERP implementation, such as the organizational improvement as being on time, and on a budget [2]. Matende and Ogao [3] in their research stated that users' involvement in providing ERP system and running it will contribute to the successful ERP implementation. A research by Nah et. al., [4] suggests that the ERP implementation in the stage of monitoring and evaluation of performance, as well as in the stage of maintenance will be affected by some factors as business process re-engineering and minimum customization, software development, testing and troubleshooting, monitoring and evaluation of performance.

Engineering systems require an automation system to run production machines that is directly integrated with the company's computer system. This integration process is carried out with business process reengineering automation systems in producing operational and process improvements in manufacturing companies. The automation process requires updated software and hardware to fit. The current process of automation is widely used by companies in running production machines that are automatically connected to the company's administrative system.

Currently, ERP has become an integrated system in the implementing companies, as it is used by all departments and decision makers in these companies. The ERP postimplementation needs to be continuously adjusted to match the companies' functions and the ever-changing situation in the companies. The changes will result in a cultural shift in the company to pay closer attention to the information quality, information technology infrastructure, and top management's commitment to ensuring ERP existence in order to benefit the company. Previous researchers have been discussing the ERP post-implementation, such as one conducted by Ajer and Hustad [5] which postulates several determining factors of ERP successful post-implementation on franchise companies. ERP post- implementation success factors will be determined by the technology aspects, which consist of the project management and system configuration, the environmental aspects, and the organization aspects, which consist of the leadership involvement and organization fit [6]. A research by $\mathrm{Yu}$ [7] suggests many variables contributing to the successful implementation of ERP in different stages, starting with preimplementation, during implementation and post-implementation. Determining factors in the post- implementation stage, such as Degree of data accuracy, Degree of system stability, Degree of user- friendliness, Size of the induced ERP system, and Integration of the ERP system implementation. Nicolaou and Bhattachary [8] suggest that the postimplementation will be determined by add-ons or ERP upgrade which has been adjusted to the organization's needs and the company's financial performance. The impact of ERP system in post-implementation from the user's perspective is being discussed in Hsu et al. [9], which state the significant positive impact of the quality system towards service quality and information quality in the post-implementation stage towards the increase of employee extended use. This is normally described as the post-implementation stage. In this stage of post-implementation, the company will continuously apply renewal of ERP system in order to be able to maintain connection and integration with the rest of the system run by the company. This would create a fully integrated system which is commonly known as the extended ERP.

The application of extended ERP will enable the company to obtain a high quality information. This high quality of information will benefit the company in improving the company's performance due to the shorter response time to the departments' needs [10]. Conceptually, the information quality dimensions are determined by the data accuracy, data quantity, completeness, objectiveness, reliability, and verifiability [11]. The information quality in the context of manufacturing companies will require data 
completeness which can be accessed by other departments and connected to the ERP system to produce a good collaboration. The existence of good collaborate on in the company will create integration in sustaining ERP system. However, the fact indicates that many companies do not pay attention to upgrade their ERP software to the latest version. This unawareness of the company makes the ERP system, i.e., hardware and software, only function as an administrative tool only. The consequence of this situation is resulting in incapability of the management in accessing appropriate information required in decision making. Only very few studies focus on the direct influence of ERP upgrading to the company performance.

\section{Organization commitment}

ERP system has become a common system that is used by almost all employees and departments in many companies. The benefits from the usage of the ERP system will only be gained from the constant updates of the system, which allow the company to cope with the changes in the operation. Any changes in the company process require the management commitment in the form of funding, assigning new responsibility to key users, and providing proper trainings for the ERP users and developers. The system will continuously evolve until it is considered as sufficient by the top management. The management commitment will become the prerequisites to synchronize the company's internal situation with the changes in the companies' external environment. This process of comparing company's internal and external conditions will help the company comprehend better its strengths and weaknesses, which will help the company to come up with a strategy to modify its ERP system. A research by Zhu et al., [6] suggests that the management's role in the ERP postimplementation will be in the form of organizational readiness. The commitment built by the organization will be in the form of how the organization successfully convinces its employees to be voluntarily and loyally involved in the organizational. Organization management needs to fully build a good relationship between each department and each employee within the organization to achieve the targets that are set by the company.

Building organization commitment will preserve the process stability and productivity in their efforts to reach the goals. This can be identified in the following three components, affective, continuance, and normative commitment. The affective commitment is described as an employee's emotional involvement towards his/her organization, and manifested in the feeling of love to the organization. Continuance commitment is described as employee's perception of costs and benefits of leaving the organization. Normative commitment is described as a moral dimension based on obligatory feelings and a sense of responsibility towards the organization. The measurement in this research is adopting Caki et al., [13] with three components, consists of affective, continuance, and normative commitment. The development applied and being used as the indicators are delightful in working, delightful in the involvement of completing the jobs, the absence of intention to leave the organization, doing the job well, and responsibility towards the job.

\section{Information quality}

ERP implementation in the company will result in the interconnection between modules in the company's business system. Order acceptance in manufacturing company will provide data entry in sales and distribution module. This entry in the sales and distribution module will be automatically connected to modules in production planning, modules in materials management, and other modules in the company. Interconnection will ensure the validity of the data and process. This will produce the desired report which matches the needs of the 
users in the departments and the output of the ERP system. The fast transformational process of the data entered into an accurate report will become a necessity for the company's decision making. This output of the ERP system in manufacturing companies will be known as information quality.

Information quality is very important for companies as it will provide the right information for decision-makers. Information quality users include customers, employees, and the company's management. This is a multi-dimensional concept. According to Marinagi et al., [10] information quality dimensions are believability, interpretability, valueadd, reputation, completeness, objectiveness, reliability, timeliness and response time, price, accuracy, availability, latency and response time. The information quality would be influenced by accuracy data, amount of data, completeness, objectiveness, reliability, and verifiability. However, it is not influenced by availability, believability, concise representation, consistent representation, relevancy, timeliness, and understandability in the case of information security practitioners in Malaysia [11]. This research will use indicators which have been adjusted to manufacturing companies' condition such as data accuracy, completeness, objectiveness, reliability, timeliness and relevancy data.

\section{Update ERP in Automtic System}

Ensuring the ERP system running smoothly during its implementation can be considered as suitable for the company's goals. Building IT structure in the company can be done simultaneously with the day-to- day operation of the company. Manufacturing companies must be able to provide IT infrastructure which is met by the basic requirements of the ERP system. The ERP implementation requires two infrastructures regarding ERP softwares and ERP hardwares. ERP software can be fulfilled by either buying available existing ERP packages, as well as building and developing company's personalized softwares. Buying an existing ERP package means that the company buying a standardized system which requires further customization to match with the company's operational system. The success of ERP implementation will heavily depend upon the quality of company IT infrastructure. The already installed ERP system is able to run the automatic system of the machines that exist in the company so that there is a synergy between the running production system and the company's computer system. The availability of a high quality IT infrastructure will produce a high-quality system with good data integration in all the departments in the company, especially in the effectiveness and efficiency of back office and front office [14]. Companies which implement ERP will most likely have software and hardware for their daily operation. Nevertheless, the company needs to update this software and hardware to match the requirement of the more advanced system. This continuous update is a necessity for the implementation of a sustainable ERP which knows as the extended ERP or ERP postimplementation. Adjusting the IT development for ERP system will provide a good administration system, making it easier for the user in applying the ERP system, and would enable information sharing across departments to support fast and accurate decision making [15]. ERP in the post-implementation stage is not only relying on the infrastructure as being used in company operation, but it requires a continuous update to increase its capabilities in dealing with job activities. Post-implementation can be acknowledged when the companies have been using ERP system for at least two years and continuously conducting the necessary upgrades infrastructures to fulfill the companies' demands [8]. The indicators for measuring ERP infrastructures: data integration, system stability, and system upgrade and technology utilization. 


\section{ERP performance}

ERP technology provides a positive contribution to the companies which have been implementing it. The ERP technology implementation will improve the company's operational capabilities and provide both tangible and intangible benefits [8]. The ERP application can also reduce the number of stocks or company inventory because decisionmakers can quickly follow the inventory level in the fields through the ERP report. Under this circumstances, they can manage the purchasing activity, and control the output and input in the company's warehouse. Applying ERP can also help to control the inventory turnover which will increase the company's profitability. Business performance can be reflected by the effective and efficient usage of the company resources, productivity, quality improvement and product/service innovation [16]. Another research suggests that company performance is measured using five indicators, which are the improvement in job performance, the pace in completing the individual task, the productivity of job, making the job more manageable, and overall satisfaction towards ERP system as a whole [17]. The indicators being used to measure the performance are easiness in decision making, shorter business process, easiness in resource management, decreased inventory level and easiness in analyzing company's condition.

\section{Conceptual the research}

Preserving ERP implementation stability for the companies in the post-implementation will be defined as improving or at least preserving the quality of information. A research by Zhou et al., [18] postulates that overall business is determined by the information quality. Similarly, the ERP implementation, which has been useful in helping companies, needs to be sustained by customizing the system through upgrading the ERP system. This process must be supported by the organizational commitment. The infrastructure upgrade requires a substantial cost and extended time in customization to match with the company situations. Customization which implemented in redesigning company's processes needs to assisted by an expert consultant or experienced capable key users [19]. The upgrade process is considered completed when the system is running smoothly and can be used by the key users in the day- to-day operation. There are six hypothesis constructed. The first hypothesis is that the organizational commitment contributes significantly to updating ERP infrastructures. The second hypothesis is that the organizational commitment has a significant direct impact to the ERP performance. The third hypothesis is that the organizational commitment contributes significantly towards the information quality. The fourth hypothesis is that the updated ERP infrastructure improves the information quality in maintaining ERP. The fifth hypothesis is that the updated ERP infrastructure improves the companies ERP performance. The sixth hypothesis is that the well-maintained information quality brings improvement to the ERP performance.

\section{Research method}

This research rook data from companies which implemented ERP in East Java, Indonesia. Based on the data from the government service on Trades and Industries, there were 234 manufacturing companies in the province of East Java. The sample was determined using purposive sampling to fulfill the sets of criteria made by the researchers. The questionnaire was distributed to 110 manufacturing companies which had been implementing and upgrading the ERP system. The distribution and visitation by ten surveyors resulting in 90 valid questionnaires could be processed further. Eight questionnaires were not submitted on 
time, 12 questionnaires were not fully filled, and two questionnaires had some partial lost data.

Based on the ERP software used by the companies, the respondents' profile was as following: 26 companies were using SAP (29\%), seven companies were using Oracle (8\%), three companies were using MFG Pro (3\%), one company was using JD Edwards (1\%), six companies were using People soft (7\%), eight companies were using Dynamics Microsoft NAV ( $9 \%$ ) and other 39 companies were using their self-developed software (43\%) by hiring local consultants or the companies' internal programmers. Based on their level in management of the companies, the respondents could be classified as following: manager 37 respondents $(41 \%)$, IT coordinator 2 respondents $(2 \%)$, owner/CEO 9 respondents $(8 \%)$, superintendent 17 respondents (18\%), sssistant manager 11 respondents (13\%), supervisor 12 respondents $(13 \%)$ and financial controller 2 respondents $(2 \%)$.

The research was using PLS as its analyzing tools by computing the model fit of the tools in measuring outer model and inner model. The measurement model used was following the variables represented in the measurement indicators. The outer model was evaluated for ensuring the validity and reliability of the construct. Measuring reliability in PLS was done using composite reliability. The reliability value had to be higher than 0.7 to be considered as reliable. The data processed resulting 0.871 for organizational commitment, 0.850 for upgrade ERP, 0.846 for information quality and 0.899 for ERP performance. The third measurement model was computed the value of influence for each variable (table 1).

Table 1. Path Coefficient.

\begin{tabular}{|c|c|c|c|c|}
\hline Effect of Variable & ginal sample estimate & $\begin{array}{c}\text { Mean of } \\
\text { subsamples }\end{array}$ & $\begin{array}{c}\text { Standard } \\
\text { deviation }\end{array}$ & T-Statistic \\
\hline Org. Comm -> Upgrade ERP & 0.537 & 0.601 & 0.092 & 5.828 \\
\hline Org. Comm -> Inf. Quality & 0.408 & 0.380 & 0.113 & 3.605 \\
\hline Upgrade ERP -> Inf. Quality & 0.408 & 0.426 & 0.081 & 5.009 \\
\hline Org. Comm -> ERP Perform & 0.274 & 0.293 & 0.158 & 1.730 \\
\hline Upgrade ERP -> ERP Perform & 0.054 & 0.061 & 0.165 & 0.329 \\
\hline Inf. Quality -> ERP Perform & 0.389 & 0.354 & 0.177 & 2.199 \\
\hline
\end{tabular}

Coefficient path (table 1) resulted in the influence of organizational commitment towards upgrade ERP infrastructure is 0.537 with t-statistic of $5.828>1.96$. This result indicates that there is a significant positive influence on organizational commitment to upgrade ERP infrastructure. This can be interpreted as the increase in organizational commitment significantly increases the upgraded ERP infrastructure. Therefore the first hypothesis can be accepted. The coefficient path for organization commitment towards information quality is 0.408 with a t-statistic of 3.605 , which is higher than 1.96 . This can be concluded that there is significant positive influence between the organization commitments towards the information quality. This means that an increase in the organization commitment will result in a significant increase in the information quality. Thus the second hypothesis can be accepted. As for the organization commitment towards the ERP performance, the coefficient path is 0.274 with t-statistic of $1.730<1.96$. This indicates that there is no significance between the organizational commitment and the ERP performance. Therefore, the third hypothesis is not accepted. The coefficient path for the influence of the upgraded ERP infrastructure towards the information quality is 0.408 with t-statistic of

$5.009>1.96$. This suggests that the increase in upgraded ERP infrastructure variable will result in the significant increase of the information quality. Thus, the fourth hypothesis can 
be accepted. The impact of the upgraded ERP infrastructure to the ERP performance is 0.054 with t-statistic of $0.329<1.96$. This suggests that the increase in the upgraded ERP infrastructure will not be able to bring any significant increase in the ERP performance. In the case, the fifth hypothesis is rejected. The path coefficient for the information quality to the ERP performance is 0.389 with t-statistic of $2.199>1.96$. This result concludes that there is a significant positive influence of the information quality to the ERP performance in manufacturing companies. An increased information quality will bring a significant increase in the ERP performance, which leads to the acceptance of the sixth hypothesis.

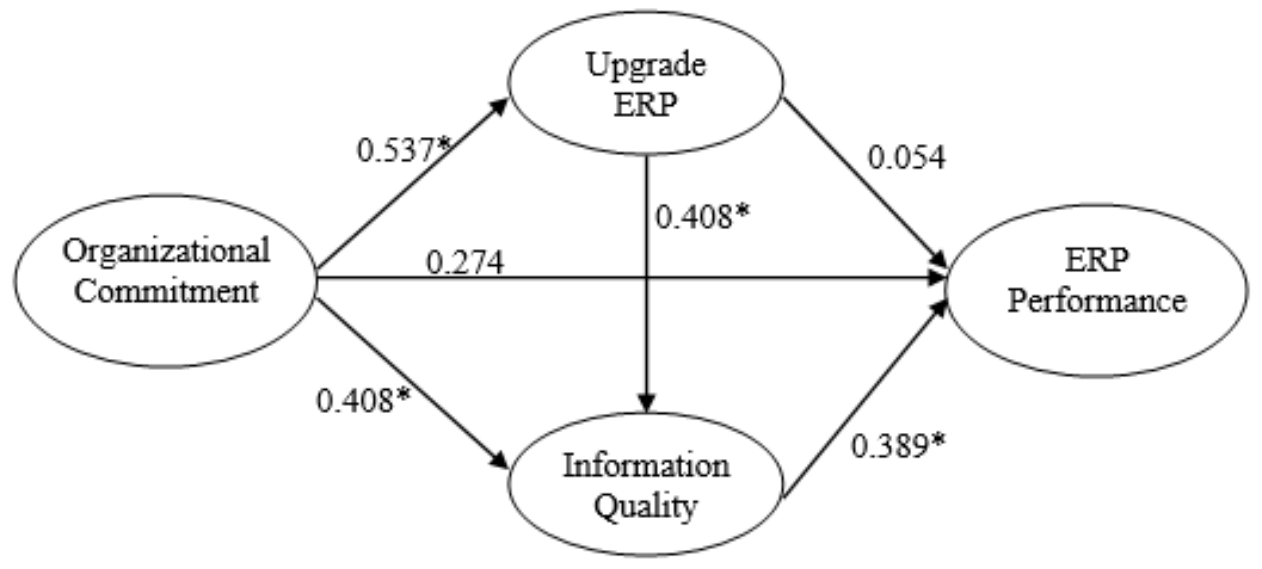

Fig. 1. Full Model Effect Organizational Commitment to ERP Performance.

This result indicates that the total influence of the organizational commitment on the ERP performance with information quality and upgrade ERP are intervening variabel high as shown by the path coefficient of 0.518 .

\section{Discussion and conclusion}

The ERP post-implementation requires active efforts to maintain its system stability to be able to produce improvement in the companies' performance. The research hypothesis tests are resulting in four accepted hypothesis and two rejected hypothesis. The first accepted hypothesis is the organizational commitment having a significant positive influence to the upgraded ERP infrastructure in East Java manufacturing companies. This influence indicates that organizational commitment in the East Java manufacturing companies, in the form of employees active involvement in the task completion and the absence of intention to leave the companies in the foreseeable future, will fasten the upgrade of the ERP system. This will improve the data integration and help the companies in making a more accurate decision. The second accepted hypothesis is the significant positive influence of the organizational commitment towards the information quality. This suggests that the organization commitment, in the form of active involvement and lack of desires to leave the company, will shape the data completeness on the ERP system and the good reliability of the system, will be preserved, which will positively contribute to a better proper decision. The third accepted hypothesis is the fast upgraded ERP infrastructure and better data integration will complete the data in the ERP system. This will result in the well-maintained reliance on the ERP system. This research is aligned with a research by Hsu et al., [9] which suggest a stable ERP system supporting a good information quality. The fourth accepted hypothesis is suggesting that the information quality which depends on a reliable well-maintained system will result in a lower level of inventory. The rejected hypothesis suggests that the 
organizational organizational commitment is merely a statement which would not produce a real result in terms of companies' operation without a tangible action in this case by having upgraded ERP infrastructure and through good information quality measurement would affect the sustainability of ERP system and would result in performance improvement [10]. This research could be further developed by focusing more on the level of management commitment in upgrading the ERP infrastructure.

\section{References}

1. P. Mandal, K. Bagchi, Ind. Manag. Data Syst. 116(6), 1259-78 (2016)

2. J. Bradley, Int. J. Account. Inform. Syst. 9(3), 175-200 (2008)

3. S. Matende, P. Ogao, Procedia Tech. 9, 518-26 (2013)

4. F.F.H. Nah, J.L.S. Lau, J. Kuang, Bus. Proc. Manag. J. 7(3), 285-97 (2001)

5. A.K. Ajer, E. Hustad, Procedia Comp. Sci. 64, 948-56 (2015)

6. Y. Zhu, Y. Li, W. Wang, J. Chen, Int. J. Inf. Manag. 30, 265-76 (2010)

7. C.S. Yu, Ind. Manag. Data Syst. 105(1), 115-32 (2005)

8. A.I. Nicolaou, S. Bhattacharya, Int. J. Account. Inform. Syst. 7, 18-35 (2006)

9. P.F. Hsu, H.R. Yen, J.C. Chung, Inf. Manag. 52(8), 925-42 (2015)

10. C. Marinagi, P. Trivellas, P. Reklitis, Procedia Soc. Behav. Sci. 175, 473-9 (2015)

11. P. Shamala, R. Ahmad, A. Zolait, M. Sedek, J. Inf. Sec. Appl. 36, 1-10 (2017)

12. P. Ifinedo, B. Rapp, A. Ifinedo, A. Sundberg, Comput. Human Behav. 26(5), 1136-48 (2010)

13. L.N. Asfuroglu, O. Erbas, Procedia Econ. Fin. 26, 1007-13 (2015)

14. S. Candra, Procedia Soc. Behav. Sci. 65, 141-9 (2012)

15. N. Nahar, Inf. Manag. 43(5), 663-77 (2006)

16. W Suprapto, Z J H Tarigan, S R Basana, ICEMT' 17 Proc., 87-91 (2017)

17. J.H. Park, H.J. Suh, H.D. Yang, Inf. Manag. 44, 300-12 (2007)

18. H. Zhou, Y. Shou, X. Zhai, L. Li, C. Wood, X. Wu, Int. J. Prod. Econ. 147, 624-33 (2014)

19. J.H. Wu, Y.M. Wang, Comput. Human Behav. 23(3), 1582-96 (2007) 